\title{
LONGEVIDADE DE LARVAS INFECTANTES DE TRICOSTRON- GILÍDEOS (NEMATODA:TRICHOSTRONGYLOIDEA) EM DUAS ALTURAS DE PASTO DE Brachiaria brizantha CV. MARANDU, DURANTE O PERÍODO DAS ÁGUAS, NO TRIÂNGULO MINEIRO
}

\author{
LONGEVITY OF INFECTIVE TRICHOSTRONGILID LARVAE \\ (NEMATODA:TRICHOSTRONGYLOIDEA) IN SAMPLES OF Brachiaria brizantha \\ CV. MARANDU OF TWO DIFFERENT HEIGHS,DURING THE RAINY SEASON, \\ AT TRIANGULO MINEIRO REGION- BRAZIL
}

\author{
R. F. M. MOTA ${ }^{1,2}$, M. C. C. URZEDO ${ }^{1,3}$, S. A. S. MACEDO ${ }^{1,4}$; R. P. MENEZES 5 , \\ M. E. R. SANTOS, F. ROSALINSKI-MORAES ${ }^{5,6^{*}}$
}

\section{RESUMO}

Uma das formas de realizar o controle dos parasitos gastrintestinais de ruminantes é limitar o desenvolvimento do estádio infectante (L3) através da modificação do microclima pelo manejo de pastagens. Para isto, torna-se necessário conhecer a viabilidade destas larvas em diferentes capins e regiões. Este trabalho foi realizado para fazer esta estimativa em capim Marandu (Brachiaria brizantha), no período das águas, na região do Triângulo Mineiro. Foram utilizados dois piquetes de $800 \mathrm{~m}^{2}$, cujo pasto apresentava altura média inicial de 10 e de $30 \mathrm{~cm}$. No dia 24 de janeiro de 2015 , dia zero do experimento, foram marcados 24 pontos em cada piquete, onde foi realizada a contaminação com $5 \mathrm{~g}$ de fezes de caprinos com média de 2100 ovos de tricostrongilídeos por grama. Amostras de pasto foram coletadas em uma área de $100 \mathrm{~cm}^{2}$ em torno do depósito de fezes, divididas em estrato superior e inferior, e submetidas ao método de Rugai modificado para obtenção e identificação das L3, nos dias 7, 14, 28 e 45 após a contaminação. Observou-se a redução do número de L3 recuperadas ao longo do tempo, sendo que esta redução foi significativa a partir do $14^{\circ}$ dia pós-contaminação ( $\left.p>0,05\right)$. Foi possível recuperar larvas em amostras de pasto até 28 dias após contaminação. Não foi observada diferença significativa pelo teste de Wilcoxon no número de larvas recuperadas a partir do estrato superior e inferior $(\mathrm{P}=0,6355)$. Também não foi observada diferença significativa no número de larvas recuperadas em amostras de pasto com 10 e $35 \mathrm{~cm}$ de altura pelo teste de Mann-Whitney $(\mathrm{p}<0,05)$. Nas condições em que o experimento foi realizado, foram recuperadas larvas infectantes até 28 dias após contaminação. Portanto, é possível inferir que diminua a contaminação de pasto com L3 se respeitado este período de descanso em sistemas de produção de ruminantes em pastejo intermitente.

PALAVRAS-CHAVE: CONTROLE INTEGRADO. L3. VIABILIDADE. $\quad$ VERMINOSE GASTRINTESTINAL.

AGRADECIMENTOS: Á FAPEMIG, pela bolsa concedida.

ÁREA TEMÁTICA: Doenças Parasitárias. 